\title{
Outcome of pneumatic retinopexy at a tertiary eye care centre in Nepal
}

\author{
Thapa R, Shrestha MK, Gurung R, Ruit S, Paudyal G \\ Tilganga Eye Centre, Kathmandu, Nepal
}

\begin{abstract}
Background: Rhegmatogenous retinal detachment is one of the commonly encountered retinal problems where timely treatment could prevent irreversible vision loss. Pneumatic retinopexy (PR) is a simple and minimally invasive procedure for retinal reattachment.

Aim: This study aimed to assess the outcome of pneumatic retinopexy in primary rhegmatogenous retinal detachment at our facility.

Study design: This was a retrospective- prospective, interventional case series.

Materials and methods: All subjects with rhegmatogenous retinal detachment who underwent pneumatic retinopexy at Tilganga Eye Centre of Nepal from January 2002 to June 2007 were included in this study.

Results: A total of 32 cases were included in the study. The mean age of patients was 55.2 year $(\mathrm{SD}=11.0)$. The majority of cases $(62.5 \%)$ presented within two weeks of symptoms with blurring of vision in $90 \%$ of cases. Pre-operatively, $56.3 \%$ (18) patients had a best corrected distance visual acuity of $<6 / 60$. Retinal detachment involving less than two quadrants consisted of $37.5 \%$ (12). A single retinal break was present in 78.1\% (25) of cases and 87.5\% (28) of the retinal breaks were located in the superotemporal quadrant. The macula was attached in $37.5 \%$ (12) of the cases. Sulfurhexafluoride and Perfluoropropane were used in 68.8\% (22) and 31.3\% (10) respectively. The average follow up period was 1.02 years (range one month to four years). The retina was completely attached in $81.3 \%$ (26) of cases at the last follow up. The best corrected distance visual acuity of 6/18-6/60 was found in 40.6\% (13) of subjects in the last follow up. There was a transient rise in intraocular pressure in $6.3 \%(2)$ of subjects after the procedure.

Conclusion: The anatomical success rate following pneumatic retinopexy is quite high $(81.3 \%)$ with good visual recovery and less morbidity translating to higher productivity for the patient. This procedure, being quicker than the alternatives, will also save surgeon's time making PR a good choice for managing primary rhegmatogenous retinal detachment in countries like Nepal where resources are scarce.
\end{abstract}

Key words: Rhegmatogenous retinal detachment, retinal break, pneumatic retinopexy, Nepal

$\mathrm{R}$ etinal disorders are the third leading cause of bilateral blindness $(3.3 \%)$ and the eighth leading cause among unilateral blindness $(3.8 \%)$ in Nepal ${ }^{1}$. Among them, Retinal Detachment (RD) is one of the common retinal problems in which timely treatment can prevent irreversible vision loss. A previous study in Nepal showed that $70 \%$ of the vitreoretinal procedures were performed exclusively for rhegmatogenous retinal detachment $(\mathrm{RRD})^{2}$. Trauma, pseudophakic eyes and high myopia were the major risk factors for RRD'.

Pneumatic retinopexy (PR) was first proposed by Dominguez (1985) and later by Hilton and Grizzard on $1986^{3}$ as an alternative surgical procedure to scleral buckling (SB) for treatment of primary RRD. When compared with SB, PR reduces the likelihood of ocular trauma, avoids hospitalization and has fewer complications.
$\mathrm{PR}$ is indicated as the appropriate surgical treatment of primary RRD where one or more retinal tears are no larger than one clock hour and are located within the superior eight clock hours of the retina, without any proliferative vitreoretinopathy changes ${ }^{4}$. This procedure is also used to treat recurrent retinal detachment following a failed SB.

In developing nations like Nepal, PR is not a commonly performed procedure because most patients do not seek medical attention soon enough following development of the visual problem. This is probably due to lack of awareness, poor transportation infrastructure and

Correspondence

Mohan Krishna Shrestha

Tilganga Eye Centre, Kathmandu, Nepal

E-mail: research@tilganga.com.np 
scarcity of specialized eye care facilities. To the best of our knowledge, there has been no data published on the outcome of PR in Nepal. We hope this study will provide some baseline data on the outcomes of PR performed at a tertiary eye care centre in Nepal.

\section{Materials and methods}

This was a retrospective- prospective, interventional case series that was executed at Tilganga Eye Centre, a tertiary eye care centre in Nepal. All patients who underwent pneumatic retinopexy from January 2002 to June 2007 were included as subjects in this study. Subjects who were not followed up within one month were excluded from the study. Hospital records were reviewed to obtain demographic data, presenting complaints, duration, and other associated ocular and systemic problems.

The examination findings recorded were visual acuity, anterior segment findings, severity of detachment, types as well as site of retinal tears, and associated proliferative vitreoretinopathy changes. Posterior segment examination was done with the help of Volk $90 \mathrm{D}$ and 20D lens.

All the subjects were evaluated and decision for PR was made by the vitreoretinal surgeon. All the subjects included in the study were primary cases of RRD with recent bullous RRD without any proliferative vitreoretinopathy changes demonstrating retinal break(s) in the superior 8 clock hours and the extent of any retinal break(s) not exceeding one clock hour. Patients unable to co-operate in proper post-operative positioning were excluded from the study.

The procedure was done under either retrobulbar or peribulbar local anesthesia. Intraoperatively, cryotherapy was applied at the retinal breaks in all cases. Intravitreal injection of $100 \%$ Perfluoropropane (C3F8) of $0.3 \mathrm{cc}$ or Sulfurhexafluoride (SF6) of $0.5 \mathrm{cc}$ was given. Paracentesis was done intraoperatively in cases with a high intraocular pressure (IOP). After intravitreal gas injection, patients were initially kept in a face down position for five to ten minutes. The head position was maintained depending upon the site of retinal break(s) so that gas bubbles would come in contact with the retinal break for minimum of five days, 16 hours a day or until the retina was completely attached. Postoperatively, patients were prescribed a combination of dexamethasone and chloramphenicol topical eye drops four hourly to start with. This dose was tapered and stopped within one month. Tropicamide eye drops were also prescribed for two weeks. Systemic Ibuprofen $400 \mathrm{mg}$ was prescribed as needed. Those cases that had high IOP were treated with anti-glaucoma drugs depending upon the severity. None of the patients were admitted to a bed.
Subsequent laser or reinjection of gas was given where the volume of gas was thought to be inadequate. Visual acuity, anatomical attachment and significant complications were noted postoperatively until their last follow up.

Ethical approval was obtained from the institutional review board of the Tilganga Eye Centre. Verbal as well as written consent was taken before surgery.

Data collection sheets were prepared for data collection. Data was edited and coded then entered in SPSS software version 11.5. Descriptive statistics were generated by SPSS and the Fisher's exact test was done in Epi Info 2000. A p-value of less than 0.05 was considered as significant.

\section{Results}

A total of 32 eyes from 32 patients were included in the study. The mean age was 55.2 years $(\mathrm{SD}=11.0)$ ranging from 30 to 73 years. About one-third of the patients were in the age range of $50-59$ years $(31.3 \%)$ followed by 60 69 years $(28.1 \%)$. More males $(62.5 \%)$ were presented in the study than females $(37.5 \%)$.

The most common presenting complaint was blurring of vision $(90.62 \%)$, followed by floaters $(6.3 \%)$ and then flashes of light (3.1\%). The majority of patients presented within one week of symptoms (37.5\%). High myopia ( $>6$ dioptres) was found in $6.3 \%$ of subjects. Aphakia, pseudophakia and subluxated lens had similar distribution (3.1\% each). Subtotal RD accounted for the majority of cases $(46.9 \%)$, whereas localized superior $\mathrm{RD}$ involving less than two quadrants was present in $37.5 \%$ of cases. In $78.1 \%$ of cases, there was a single retinal break, while the remainder $(21.9 \%)$ had multiple breaks involving less than one clock hour. The retinal tears were primarily superotemporal $(87.5 \%)$, followed by superonasal $(9.4 \%)$ and superior (3.1\%). The macula was not involved in the RD for $37.5 \%$ of cases. SF6 was used in the majority of cases $(68.75 \%)$ as compared to C3F8 (31.3\%).

The majority of patients had a preoperative best corrected visual acuity (BCDVA) of less than 6/60 (56.3\%) with BCDVA of $6 / 6-6 / 18$ present in $25 \%$ of patients. There was marked improvement of vision after surgery, evidenced by a BCDVA of 6/18-6/60 in 40.6\% of cases at the last follow up. $18.8 \%$ of cases maintained a good vision of 6/6-6/18 (Table 1, 2).

The retina was completely flat in $53.1 \%$ of the cases on the first post- operative day follow up. At the last follow up, the retina was attached in $81.3 \%$ of cases. 
The average follow up period of our study cases was 1.02 years, which ranged from one month to four years.

In $71.8 \%$ of the cases, the retina was attached with a single procedure. Subsequent laser therapy was given in four cases. Reinjection of gas was needed in three cases where the gas bubble was determined to be inadequate. Including these cases, the total anatomical attachment success rate increased to $81.3 \%$. Anatomical attachment had not been achieved in $18.8 \%$ of the cases at their last follow up. Among these retinopexy failure cases, two were managed with scleral buckling and four cases with Pars plana vitrectomy and internal temponade with silicon oil.
In our study, we found an increased failure rate in subjects older than 50 years, subjects with subtotal RD, multiple retinal tears, or high myopia ( $>6$ Dioptre) and in subjects who underwent PR with C3F8 gas. However, none of these factors were statistically significant.

In $75.0 \%$ of cases, the intra-operative and post-operative course was uneventful without any complications. Increased intraocular pressure was found in $6.3 \%$ of subjects and failure of the surgery occurred in nearly $18.8 \%$ of cases (Table $3,4,5$ ).

Table 1: General characteristics

\begin{tabular}{|c|c|c|c|}
\hline \multicolumn{2}{|l|}{ Variables } & Frequency & Percentage $(\%)$ \\
\hline \multirow{5}{*}{$\begin{array}{l}\text { Age (Years) } \\
(n=32)\end{array}$} & $30-39$ & 2 & 6.3 \\
\hline & $40-49$ & 8 & 25.0 \\
\hline & $50-59$ & 10 & 31.3 \\
\hline & $60-69$ & 9 & 28.1 \\
\hline & $70-79$ & 3 & 9.4 \\
\hline \multirow{5}{*}{$\begin{array}{l}\text { Duration of symptoms in } \\
\text { weeks }(n=32)\end{array}$} & $0-1 \mathrm{wk}$ & 12 & 37.5 \\
\hline & $1-2 \mathrm{wk}$ & 8 & 25.0 \\
\hline & $2-4 \mathrm{wk}$ & 6 & 18.8 \\
\hline & 4-12 wk & 2 & 6.2 \\
\hline & $>12 \mathrm{wk}$ & 4 & 12.5 \\
\hline \multirow{3}{*}{$\begin{array}{l}\text { Extent of retinal detachment } \\
(n=32)\end{array}$} & Subtotal & 15 & 46.9 \\
\hline & Localized superior ( $\leq 2$ quadrants) & 12 & 37.5 \\
\hline & Total RD & 5 & 15.6 \\
\hline \multirow{3}{*}{ Site of retinal breaks $(n=32)$} & Superior & 1 & 3.1 \\
\hline & Superior nasal & 3 & 9.4 \\
\hline & Superior temporal & 28 & 87.5 \\
\hline \multirow{2}{*}{ Condition of macula $(n=32)$} & Off & 20 & 62.5 \\
\hline & On & 12 & 37.5 \\
\hline \multirow{2}{*}{$\begin{array}{l}\text { Types of gas used } \\
(n=32)\end{array}$} & Perfluoropropane (C3F8) & 10 & 31.3 \\
\hline & Sulfurhexafluoride (SF6) & 22 & 68.7 \\
\hline
\end{tabular}

Table 2: Visual acuity before and after surgery $(n=32)$

\begin{tabular}{|l|l|c|c|c|c|}
\hline \multicolumn{2}{|l|}{ Description } & $\mathbf{6 / 6 - 6 / 1 8}(\mathbf{n} / \mathbf{p})$ & $<\mathbf{6 / 1 8 - 6 / 6 0}(\mathbf{n} / \mathbf{p})$ & $<\mathbf{6 / 6 0 - 3 / 6 0}(\mathbf{n} / \mathbf{p})$ & $<\mathbf{3 / 6 0}-\mathbf{p l}(\mathbf{n} / \mathbf{p})$ \\
\hline \multirow{4}{*}{ Uncorrected } & Pre-op & $6(18.8)$ & $5(15.6)$ & $1(3.1)$ & $20(62.5)$ \\
\cline { 2 - 6 } & Day 1 post-op & $6(18.8)$ & $10(31.3)$ & $3(9.4)$ & $13(40.5)$ \\
\cline { 2 - 6 } & Last follow-up & $6(18.8)$ & $13(40.6)$ & $1(3.1)$ & $12(37.5)$ \\
\hline \multirow{3}{*}{ Best Corrected } & Pre-op & $8(25.0)$ & $4(12.5)$ & $2(6.3)$ & $18(56.3)$ \\
\cline { 2 - 6 } & Day 1 post-op & $7(21.8)$ & $11(34.4)$ & $3(9.4)$ & $11(34.4)$ \\
\cline { 2 - 6 } & Last follow-up & $6(18.8)$ & $13(40.6)$ & $1(3.1)$ & $12(37.5)$ \\
\hline
\end{tabular}

$\mathrm{n} / \mathrm{p}=$ number (percentage) 
Table 3: Anatomical success after pneumatic retinopexy

\begin{tabular}{|l|c|c|}
\hline Retina & Day 1 post-op $(\mathrm{n} / \mathrm{p})$ & Last follow up $(\mathrm{n} / \mathrm{p})$ \\
\hline Flat & $17(53.1)$ & $26(81.3)$ \\
\hline Sub retinal fluid & $15(46.9)$ & $6(18.7)$ \\
\hline Total & $32(100)$ & $32(100)$ \\
\hline
\end{tabular}

Table 4: Pattern of surgical procedures $(n=32)$

\begin{tabular}{|l|c|c|}
\hline Procedures & Number & Percentage \\
\hline Single injection of gas & 23 & 71.9 \\
\hline Reinjection of gas & 3 & 9.3 \\
\hline Vitrectomy with Silicon Oil & 4 & 12.5 \\
\hline Scleral buckling & 2 & 6.3 \\
\hline
\end{tabular}

Table 5: Factors associated with success and failure of retinal attachment

\begin{tabular}{|c|c|c|c|}
\hline Factors associated & Success $(\mathrm{n} / \mathrm{p})$ & Failure (n/p) & $\mathrm{p}$ value \\
\hline \multicolumn{4}{|l|}{ Age group } \\
\hline Age $<50$ Years & $8(80.0)$ & $2(20.0)$ & \multirow[b]{2}{*}{1.00} \\
\hline Age $\geq 50$ Years & $18(81.8)$ & $4(18.2)$ & \\
\hline \multicolumn{4}{|l|}{ Duration of presentation } \\
\hline 0 -2 weeks & $18(90.0)$ & $2(10.0)$ & \multirow[b]{2}{*}{0.17} \\
\hline$>2$ weeks & $8(66.7)$ & $4(33.3)$ & \\
\hline \multicolumn{4}{|l|}{ Extent of RD } \\
\hline Subtotal/ total RD(> 2 quadrants $)$ & $17(85.0)$ & $3(15.0)$ & \multirow[b]{2}{*}{1.00} \\
\hline Localized Superior ( $\leq 2$ quadrants) & $10(83.3)$ & $2(16.7)$ & \\
\hline \multicolumn{4}{|l|}{ Retinal tear } \\
\hline Single & $21(84.0)$ & $4(16.0)$ & \multirow[b]{2}{*}{0.59} \\
\hline Multiple & $5(71.4)$ & $2(28.6)$ & \\
\hline \multicolumn{4}{|l|}{ Type of gases } \\
\hline C3F8 & $6(60.0)$ & $4(40.0)$ & \multirow[b]{2}{*}{0.06} \\
\hline SF6 & $20(90.9)$ & $2(9.1)$ & \\
\hline \multicolumn{4}{|l|}{ Condition of lens } \\
\hline Phakia & $24(80.0)$ & $6(20.0)$ & \multirow[b]{2}{*}{0.86} \\
\hline Pseudophakia/ Aphakia & $2(100)$ & 0 & \\
\hline \multicolumn{4}{|l|}{ Myopic status } \\
\hline Minimal or no myopia & $26(86.2)$ & $4(13.8)$ & \multirow[b]{2}{*}{0.03} \\
\hline High Myopia & 0 & $2(100)$ & \\
\hline
\end{tabular}

\section{Discussion}

To the best of our knowledge, this is the first reported study on outcome of pneumatic retinopexy in Nepalese patients. The average age of patients in our study, 55.2 years (range 30 to 73 years) is similar to the average age reported in $\mathrm{USA}^{5}$ which was 55 years (range 3081). Males also composed a higher proportion of their study subjects $(66 \%)$. This is similar to our findings of $62.5 \%$ male patients. Likewise, the average age and sex were comparable with the similar studies done in West Bengal $^{6}$ and Germany ${ }^{7}$.
Our single operation success rate was $71.9 \%$. Three cases needed reinjection of gas due to inadequate quantity in first procedure. The anatomical success rate was $81.3 \%$ at the last follow up. Our success rate was comparable to those reported in other studies where it ranged from $66-83 \%{ }^{5,8,9,10,11,12,13,14}$.

In a randomized controlled trial of $\mathrm{PR}$ versus $\mathrm{SB}$, Das et $\mathrm{al}^{6}$ found that anatomic results of $\mathrm{SB}$ and $\mathrm{PR}$ are not significantly different in selected cases, with final post 
operative visual acuity being better with PR which was consistent with many other literatures. Since its first description, PR has attracted more and more interest and has become established as the first choice procedure for certain kinds of RD in the USA and Canada ${ }^{15}$.

The macula was attached in $37.5 \%$ of our cases which is similar (36\%) to Lisle et al reported ${ }^{14}$ whereas it was $62 \%$ in the series reported by the Zaidi et al. ${ }^{5}$

Most of our cases were phakic (93.8\%) as is comparable to other studies ${ }^{5,14}$. High myopia was found in $6.3 \%$ of cases which is lower than the Zaidi et al $(18 \%)^{5}$.

The majority of our patients $(56.3 \%)$ had a pre operative BCDVA of less than 6/60 where as one fourth had BCDVA of 6/6-6/18. Following PR, there was marked improvement in BCDVA of $6 / 18-6 / 60$ in $40.6 \%$ cases and $18.8 \%$ of cases maintaining good vision of $6 / 6-6 / 18$ at the last follow up.

Tornambe ${ }^{8}$ found $6 / 12$ or better visual acuity in $86 \%$ of eyes in his series. Similarly, Kulkarmi et al ${ }^{16}$ described greater than or equal to $6 / 18$ visual acuity in $73.6 \%$ in the macula off RD. Ziadi et $\mathrm{al}^{5}$ found average visual acuity of $6 / 6 p$ at the final follow up, versus $6 / 24$ preoperatively. Another study in west Bengal ${ }^{6}$ showed $6 / 12$ or better vision in $88 \%$ of their series although they have not discussed pre-operative macular involvement. The lower average visual acuity in our series may be the result of poor pre-operative vision due to late presentation and pre-existing cataract, as the majority of subjects belong to an older age group.

The average follow up period of our cases was 1.02 years (ranging from one month to four years). This is similar to the follow- up period reported by Zaidi et $\mathrm{al}^{5}$ (14.9 months with a range of 1 to 66 months) but follow up period of this study was shorter than reported by Lisle et $\mathrm{al}^{14}$ (8.1 years with a range of 7.3 to 9.2$)$ and Eter et $\mathrm{al}^{7}$ ( 6.35 years). However in a series by Das et al ${ }^{6}$, they only followed up cases for six months.

Further analysis was done regarding factors associated with success and failure cases in our study group. We found an increased failure rate to be associated with the following risk factors; patient's age greater than 50 years, late presentation (after two weeks of symptoms), high myopia, use of $\mathrm{C} 3 \mathrm{~F} 8$ gas, multiple retinal breaks and subtotal RD. Excepting high myopia $(p=0.03)$, other factors were not statistically significant in our series. Our findings on factors associated with failure of retinal attachment were similar to those reported by other studies ${ }^{2,9,13}$ although in this series the data is not adequate (i.e. $>5$ subjects) to make a solid inference about the population.
The intraoperative and postoperative course was uneventful in most of our cases (75\%). We found a transient increase in intraocular pressure in $6 \%$ and failure for the retinal attachment in nearly $19 \%$ of our patients during the course of our study period. Our findings on these are comparable with many other reported studies ${ }^{5,8,9,10,11,12,13,14}$.

\section{Conclusion}

The anatomical success rate following pneumatic retinopexy is quite high $(81.3 \%)$ with good visual recovery and less morbidity translating to higher productivity for the patient. This procedure, being quicker than the alternatives, will also save surgeon's time making PR a good choice for managing primary rhegmatogenous retinal detachment in countries like Nepal where resources are scarce.

We recommend the further studies with a larger sample size and prolonged follow up in the future.

\section{References}

1. BrilliantLB, PokhrelRP, GrassetNC, Lepkowski JM, Kolstad A, Hawks W, et al. Epidemiology of blindness in Nepal. Bull World Health Organ. 1985;63(2):375-86.

2. Paudyal G, Doshi V, Shrestha MK, Kalayoglu MV, Tabin G, Gurung R, et al. Treatment of vitreoretinal disorders in the developing world: indications and outcomes of vitreoretinal surgery in Nepal. Ophthalmology. 2005 Feb;112(2):31926.

3. Hilton GF, Grizzard WS. Pneumatic retinopexy. A two-step outpatient operation without conjunctival incision. Ophthalmology 1986 May;93(5):626-41.

4. Ryan SJ. Retina. In: Brinton DA, Lit ES, eds. Pneumatic Retinopexy. 4th ed. Philadelphia, USA: Elservier Mosby; 2006. P. 2071-83.

5. Zaidi AA, Alvarado R, Irvine A. Pneumatic retinopexy: success rate and complications. $\mathrm{Br}$ J Ophthalmol. 2006 Apr;90(4):427-8.

6. Das A, Sinha K, Subbhendu B. Pneumatic retinopexy versus scleral buckling-a randomized controlled trial. AIOC 2004: retina/Vitreous; 2004. p. 333-4.

7. Eter N, Boker T, Spitznas M. Long-term results of pneumatic retinopexy. Graefes Arch Clin Exp Ophthalmol. 2000 Aug;238(8):677-81.

8. Tornambe PE. Pneumatic retinopexy: the evolution of case selection and surgical technique. A twelve-year study of 302 eyes. Trans Am Ophthalmol Soc. 1997;95:551-78. 
9. Grizzard WS, Hilton GF, Hammer ME, Taren D, Brinton DA. Pneumatic retinopexy failures. Cause, prevention, timing, and management. Ophthalmology 1995 Jun;102(6):929-36.

10. Yanyali A, Horozoglu F, Bayrak YI, Celik E, Nohutcu AF. Steamroller versus basic technique in pneumatic retinopexy for primary rhegmatogenous retinal detachment. Retina 2007 Jan;27(1):74-82.

11. Bohm P, Zahorcova M. Pneumatic retinopexy-method of choice in treatment of retinal detachment. Cesk Slov Oftalmol 2003 Jun;59(3):154-9.

12. Boker T, Schmitt C, Mougharbel M. Results and prognostic factors in pneumatic retinopexy. Ger J Ophthalmol. 1994 Mar;3(2):73-8.
13. Kleinmann G, Rechtman E, Pollack A, Schechtman E, Bukelman A. Pneumatic retinopexy: results in eyes with classic vs relative indications. Archives of ophthalmology 2002 Nov;120(11):1455-9.

14. Lisle C, Mortensen KK, Sjolie AK. Pneumatic retinopexy. A long term follow-up study. Acta ophthalmologica Scandinavica. 1998 Aug;76(4):486-90.

15. Benson WE, Chan P, Sharma S, Snyder WB, Bloome MA, Birch DG. Current popularity of pneumatic retinopexy. Retina 1999;19(3):23841.

16. Kulkarni KM, Roth DB, Prenner JL. Current visual and anatomic outcomes of pneumatic retinopexy. Retina 2007 Oct;27(8):1065-70. 